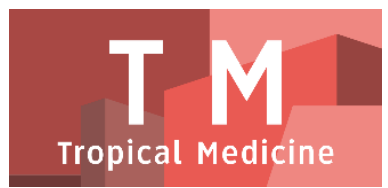

PAPER - OPEN ACCESS

\title{
Senyawa Saponin Hasil Isolasi dari Daun Buni (Antidesma bunius (L.) Spreng.)
}

Author : Hady Wiraputra

DOI $\quad: 10.32734 /$ tm.v1i1.79

Paper Page : $264-270$

Volume 1 Issue 1 - 2018 TALENTA Conference Series: Tropical Medicine (TM)

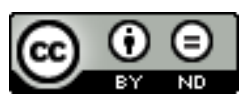

This work is licensed under a Creative Commons Attribution-NoDerivatives 4.0 International License.

Published under licence by TALENTA Publisher, Universitas Sumatera Utara
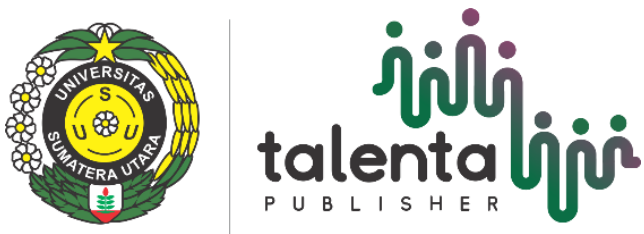


\title{
talentạlo \\ Available online at https://talentaconfseries.usu.ac.id
}

\section{Senyawa Saponin Hasil Isolasi dari Daun Buni (Antidesma bunius (L.) Spreng.)}

\author{
Hady Wiraputra $^{\mathrm{a}}$, Marline Nainggolan ${ }^{\mathrm{a}, *}$, Panal Sitorus $^{\mathrm{a}}$ \\ Fakultas Farmasi, Universitas Sumatera Utara 20155, Indonesia \\ linegolan57@gmail.com
}

\begin{abstract}
Abstrak
Tanaman buni (Antidesma bunius (L.) Spreng.) secara tradisional telah digunakan untuk hipertensi, takikardia, anemia, sifilis, antikanker, antioksidan, sumber pewarna alami dan antidiabetes. Saponin merupakan senyawa fitokimia yang mempunyai kemampuan membentuk busa dan mengandung aglikon polisiklik yang berikatan dengan satu atau lebih gula. Penelitian ini bertujuan untuk melakukan karakterisasi senyawa saponin hasil isolasi dari daun buni dengan spektrofotometer ultraviolet dan inframerah.

Simplisia daun buni dilakukan karakterisasi kemudian diekstraksi dengan cara maserasi bertingkat menggunakan pelarut n-heksana dan etanol $80 \%$. Selanjutnya ekstrak etanol dihidrolisis dengan $\mathrm{HCl} 2 \mathrm{~N}$ kemudian difraksi dengan pelarut kloroform. Isolasi dilakukan terhadap fraksi kloroform dengan cara kromatografi lapis tipis preparatif menggunakan fase diam silika gel GF254 dan fase gerak yang sesuai. Isolat yang diperoleh diuji kemurnian dengan KLT 2 arah dan dikarakterisasi menggunakan spektrofotometer ultraviolet dan inframerah.

Hasil pemeriksaan karakterisasi simplisia diperoleh kadar air 7,32\%, kadar sari larut dalam etanol 52,70\%, kadar sari larut dalam air 23,25\%, kadar abu total 6,86\% dan kadar abu tidak larut dalam asam 0,94\%. Pemisahan fraksi kloroform dengan KLT menggunakan fase gerak n-heksana-etilasetat perbandingan 5:5 diperoleh noda 13 dan hasil KLT preparatif diperoleh 2 isolat murni yaitu isolat 1 (ungu merah) dengan Rf 0,92 dan isolat 2 (biru) dengan Rf 0,78. Hasil karakterisasi isolat 1 diperoleh panjang gelombang maksimum pada $208 \mathrm{~nm}$ dan dijumpai adanya gugus hidroksil, gugus $-\mathrm{CH}$ alifatis, ikatan $\mathrm{C}=\mathrm{C}$, gugus $-\mathrm{CH} 2$, gugus $-\mathrm{CH} 3$, dan gugus $\mathrm{C}-\mathrm{O}$. Hasil karakterisasi isolat 2 diperoleh panjang gelombang maksimum pada $204 \mathrm{~nm}$ dan adanya gugus hidroksil, gugus $-\mathrm{CH}$ alifatis, gugus $-\mathrm{CH} 2$, gugus $-\mathrm{CH} 3$, dan gugus $\mathrm{C}-\mathrm{O}$.
\end{abstract}

Kata Kunci: Antidesma bunius, karakteristik, isolasi, saponin;

\section{Pendahuluan}

Indonesia merupakan negara yang kaya akan sumber daya alam hayati dan hutan tropis, salah satu adalah daerah pulau Jawa yang kaya akan tanaman berkhasiat yang digunakan secara tradisional (Kumalasari, et al., 2014), Tanaman buni (Antidesma bunius (L.) Spreng) merupakan tanaman yang digunakan masyarakat untuk mengobati darah tinggi, jantung berdebar kencang, anemia, sifilis (Wijayakusuma, et al., 1996), dan juga beberapa penelitian tentang kegunaan tumbuhan buni berupa gangguan saluran pencernaan (Kassem, 2013), antikanker (Micor, et al., 2005; Puspitasari, et al., 2009), antioksidan (Samappito, et al., 2011; Barcelo, et al., 2016), antidiabetes (Herrera, et al., 2010; Elya et al., 2012; Loranza, 2012) dan sumber zat warna alami (Amelia, et al., 
2013). Daun buni mengandung sejumlah saponin, flavonoid dan tanin dan juga buah buni mengandung antosianin, flavonoid dan asam fenolat (Butkhup, et al., 2008; Ajmiati, et al, 2014).

Saponin dapat diaplikasikan sebagai surfaktan alami, antimikroba, antijamur, obat hiperkolesterol, antitumor, antikanker, antidiabetes dan lain sebagainya (Netala, et al, 2015; Garai, 2014).

Simplisia sebagai produk hasil pertanian atau pengumpulan dari tumbuhan liar (wild crop) memilki kandungan kimia yang tidak terjamin selalu konstan karena adanya variabel bibit, tempat tumbuh, iklim, kondisi (umur dan cara panen) serta proses pasca panen dan preparasi akhir. Karakterisasi suatu simplisia mempunyai pengertian bahwa simplisia yang akan digunakan untuk obat sebagai bahan baku harus memenuhi persyaratan. (Ditjen POM, 2000).

Kromatografi merupakan cara untuk mengisolasi senyawa murni pada skala miligram sampai skala gram untuk menelaah struktur, uji biologi, uji farmakologi, senyawa pembanding dan senyawa baku untuk penentuan kuantitatif (Hostettmann, 1995).

Berdasarkan latar belakang diatas maka peneliti tertarik untuk mengisolasi senyawa saponin dari daun buni (Antidesma bunius (L.) Spreng).

\section{Metode Penelitian}

\subsection{Bahan}

Bahan-bahan yang digunakan pada penelitian ini adalah daun buni (Antidesma bunius (L.) Spreng.) dan bahanbahan kimia yang digunakan kecuali dinyatakan lain berkualitas pro analisis.

\subsection{Pengambilan Dan Preparasi Sampel}

Sampel yang digunakan dalam penelitian ini adalah daun buni yang masih segar, yang diambil dari Jalan Suwondo, Kecamatan Medan Polonia, Provinsi Sumatera Utara. Sampel didibersihkan dari kotoran kemudian dicuci dengan air bersih yang mengalir, ditiriskan kemudian dikeringkan dalam lemari pengering dengan suhu $40^{\circ} \mathrm{C}$, setelah sampel kering, diserbukkan menggunkan blender.

\subsection{Pemeriksaan Karakteristik Simplisia}

Pemeriksaan karakteristik simplisia meliputi penetapan kadar air, penetapan kadar sari larut dalam air, penetapan kadar sari yang dalam etanol, penetapan kadar abu total, dan penetapan kadar abu yang tidak larut dalam asam.

\subsection{Prosedur Ekstraksi Simplisia}

Sejumlah 500 gram serbuk simplisia dimasukkan kedalam wadah kaca bertutup, dimaserasi dengan $\mathrm{n}$ - heksana. Hasil maserasi disaring, ampas dimaserasi kembali dengan etanol 80\%. Hasil maserasi disaring, kemudian dipekatkan dengan alat penguap vakum putar pada suhu $50^{\circ} \mathrm{C}$ sampai diperoleh ekstrak kental. Kemudian ekstrak direfluks menggunakan $\mathrm{HCl} 2 \mathrm{~N}$ selama 4-6 jam. Selanjutnya filtrate diekstraksi dengan kloroform dan didiamkan selama 12-18 jam, dipekatkan. Kemudian fraksi kloroform dianalsis dengan menggunakan kromatografi lapis tipis. Aglikon saponin berada dalam lapisan kloroform. (Harbone, 1987). 


\subsection{Isolasi Senyawa Saponin Secara Kromatografi Lapis Tipis Preparatif}

Fraksi kloroform ditotolkan pada plat KLT berukuran 20x20 cm yang telah diaktifkan, dimasukkan ke dalam bejana yang telah jenuh dengan uap fase gerak. Plat disemprot dengan penampak bercak. Silika diambil dan dielusi dengan metanol p.a. hingga bersih. Filtrat diuapkan hingga terbentuk kristal.

\subsection{Uji Kemurnian Terhadap Isolat}

Uji kromatografi lapis tipis satu arah

Uji kemurnian isolat secara satu arah dilakukan dengan KLT menggunakan fase gerak n-heksana- etilasetat (8:2), fase diam plat pra lapis silika gel GF 254 serta penampang bercak Liebermann-Burchard.

\subsection{Uji kromatografi lapis tipis dua arah}

Terhadap hasil isolasi dilakukan KLT 2 arah menggunakan fase gerak n-heksana-etilasetat (8:2) dan toluenaetilasetat (5:5) fase diam plat pra lapis silika gel GF 254 serta penampang bercak Liebermann- Burchard.

\subsection{Analisis Isolat Dengan Spektrofotometer Ultraviolet (UV)}

Analisis isolat murni dilakukan dengan menggunakan spektrofotometer UV-Vis (Shimadzu).

\subsection{Karakterisasi Isolat Dengan Spektrofotometer Inframerah (IR)}

Analisis isolat murni dilakukan dengan menggunakan spektrofotometer FT-IR (Shimadzu).

\section{Tabel, Gambar dan Peta}

Pemeriksaan Karakteristik Simplisia

Table. 1. Hasil Karakterisasi Simplisia Antidesma bunius (L.) Spreng

\begin{tabular}{llll}
\hline No. & Karakteristik Simplisia & Hasil (\%) & Persyaratan(\%) \\
\hline 1. & Kadar air & $7,32 \%$ & $<10 \%$ \\
2. & Kadar sari larut dalam etanol & $52,70 \%$ & - \\
3. & Kadar sari arut dalam air & $23,25 \%$ & - \\
4. & Kadar abu total & $6,86 \%$ & - \\
5. & Kadar abu tidak larut dalam asam & $0,94 \%$ & $<2 \%$ \\
\hline
\end{tabular}

Hasil penepatapan kadar air pada simplisia daun Antidesma bunius (L.) Spreng. menunjukkan kandungan air yang masih di dalam batasan minimal yang dapat ditolerir. Kadar air yang melebihi $10 \%$ dapat menjadi media yang baik untuk pertumbuhan mikroba, keberadaan jamur, serta mendorong kerusakan mutu simplisia (WHO, 1992). Penetapan kadar sari yang larut dalam air dan etanol dilakukan untuk mengetahui banyaknya minimal kandungan terendah senyawa yang terdapat dalam simplisia baik yang larut dalam air ataupun larut dalam etanol. Kadar abu menunjukkan banyak kandungan mineral internal (abu fisiologis) yang berasal dari jaringan tanaman itu 
sendiri yang terdapat di dalam sampel (Ditjen, POM., 2000; WHO., 1992). Kadar abu menunjukkan banyaknya kandungan mineral internal (abu fisiologis) yang berasal dari jaringan tanaman itu sendiri yang terdapat didalam sampel (Ditjen POM., 2000; WHO., 1992). Kadar abu tidak larut asam untuk menunjukkan jumlah silikat, khususnya pasir yang ada pada simplisia dengan cara melarutkan abu total dalam asam klorida (WHO., 1992). Kadar abu tidak larut dalam asam memenuhi persyaratan dimana kadarnya harus tidak lebih dari 2\% (Ditjen POM, 2014).

\subsection{Ekstraksi}

Hasil ekstraksi dengan pelarut etanol 80\% diperoleh sebanyak 53,12 g. Penggunaan pelarut etanol 80\% untuk menarik semua senyawa metabolit sekunder pada daun. Hidrolisis ekstrak etanol $80 \%$ dengan $\mathrm{HCl}$ $2 \mathrm{~N}$ dengan tujuan untuk memutuskan ikatan gula dan non-gula kemudian disari dngan pelarut kloroform untuk mengektraksi senyawa saponin (Harborne, 1987).

\subsection{KLT Preparatif Pada Fraksi Kloroform}

Hasil KLT Preparatif pada fraksi kloroform menggunakan fase diam silika gel GF 254 dan fase gerak n- heksanaetilasetat (5:5) menghasilkan 13 noda berwarna ungu merah, hijau muda, biru, hijau, merah muda dan ungu. Masing-masing noda diambil secara terpisah dan dielusi dengan pelarut metanol. Terhadap noda 2, noda 4 sampai noda 13 tidak dilanjutkan karena hasil yang diperoleh sangat sedikit.

\subsection{Uji Kemurnian Isolat}

Masing-masing isolat dilakukan uji kemurnian dengan KLT 1 arah menggunakan fase gerak n-heksana- etilasetat (8:2) dan KLT 2 arah menggunakan fase gerak I n-heksana-etilasetat (8:2), fase gerak II toluena-etilasetat (5:5), fase diam plat pra lapis silika gel GF 254 dan penampak bercak Liebermann- Burchard. Hasil menunjukkan bahwa isolat 1 (noda 1) menunjukkan hasil satu noda dengan warna ungu merah dan isolat 2 (noda 3) menunjukkan hasil satu noda dengan warna biru.

\subsection{Identifikasi Isolat Saponin}

Terhadap isolat 1 dilakukan pemeriksaan karakteristik dengan spektrofotometer ultraviolet (UV) dan diperoleh panjang gelombang maksimum $208 \mathrm{~nm}$ (Gambar 1.). Hasil analisis spektrofotometer inframerah (IR) adalah gugus OH $(3406,29 \mathrm{~cm}-1)$, gugus $-\mathrm{CH}$ alifatis $(2920,23 \mathrm{~cm}-1$ dan $2854,65 \mathrm{~cm}-1)$, ikatan $\mathrm{C}=\mathrm{C}(1627,92 \mathrm{~cm}-1)$, gugus CH2 (1454,33 cm-1), gugus - $\mathrm{CH} 3(1373,32 \mathrm{~cm}-1)$ dan gugus $\mathrm{C}-\mathrm{O}(1107,14 \mathrm{~cm}-1)$. Isolat 1 diduga adalah golongan saponin triterpenoid (Gambar 2.). 


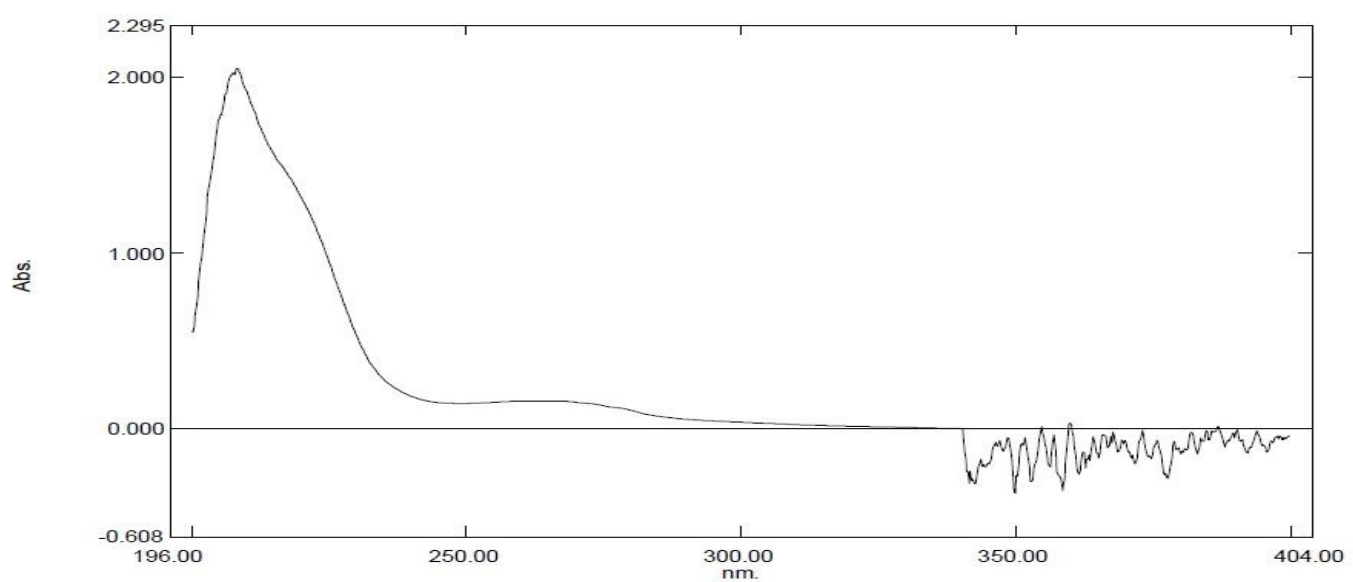

Gambar 1. Hasil identifikasi isolat 1 dengan spektrofotometer ultraviolet (UV)

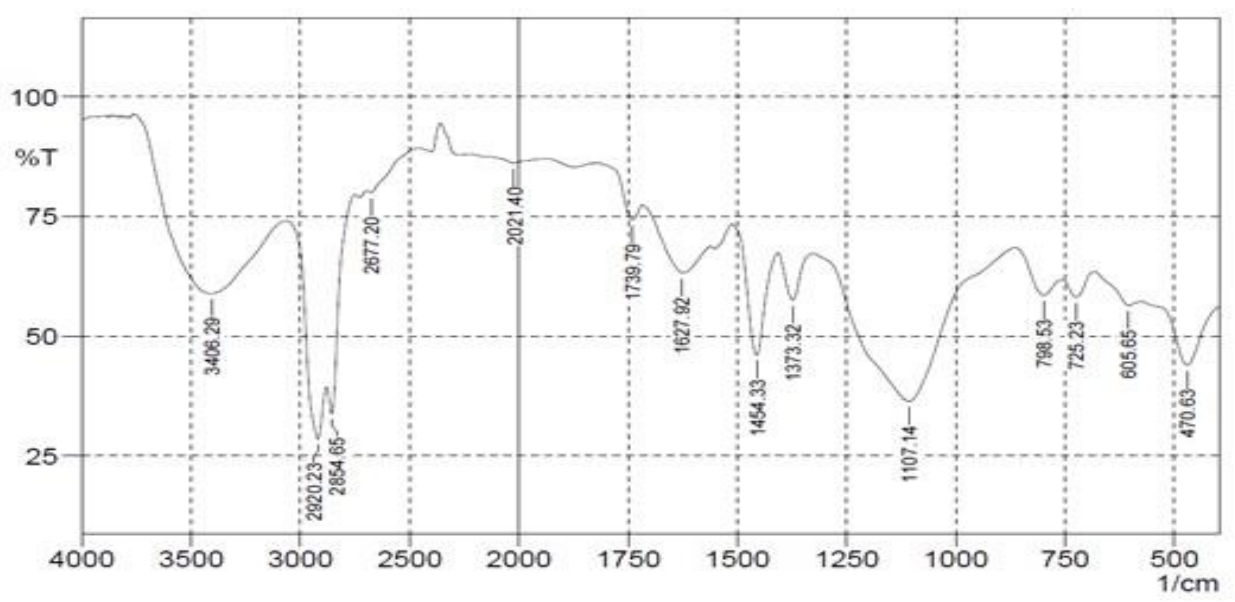

Gambar 2. Hasil identifikasi isolat 1 dengan spektrofotometer inframerah (IR)

Terhadap isolat 2 dilakukan pemeriksaan karakteristik dengan spektrofotometer ultraviolet (UV) dan diperoleh panjang gelombang maksimum $204 \mathrm{~nm}$ (Gambar 3.). Hasil analisis spektrofotometer inframerah (IR) adalah ada gugus - OH $\left(3421,72 \mathrm{~cm}^{-1}\right)$, gugus $-\mathrm{CH}$ alifatis $\left(2920,23 \mathrm{~cm}^{-1}\right.$ dan $\left.2854,65 \mathrm{~cm}^{-1}\right)$, gugus $-\mathrm{CH}_{2}\left(1458,18 \mathrm{~cm}^{-1}\right)$, gugus $-\mathrm{CH}_{3}\left(1373,32 \mathrm{~cm}^{-1}\right)$ dan gugus $\mathrm{C}-\mathrm{O}\left(1103,28 \mathrm{~cm}^{-1}\right)$. Isolat 2 diduga adalah senyawa saponin steroid (Gambar 4.). 

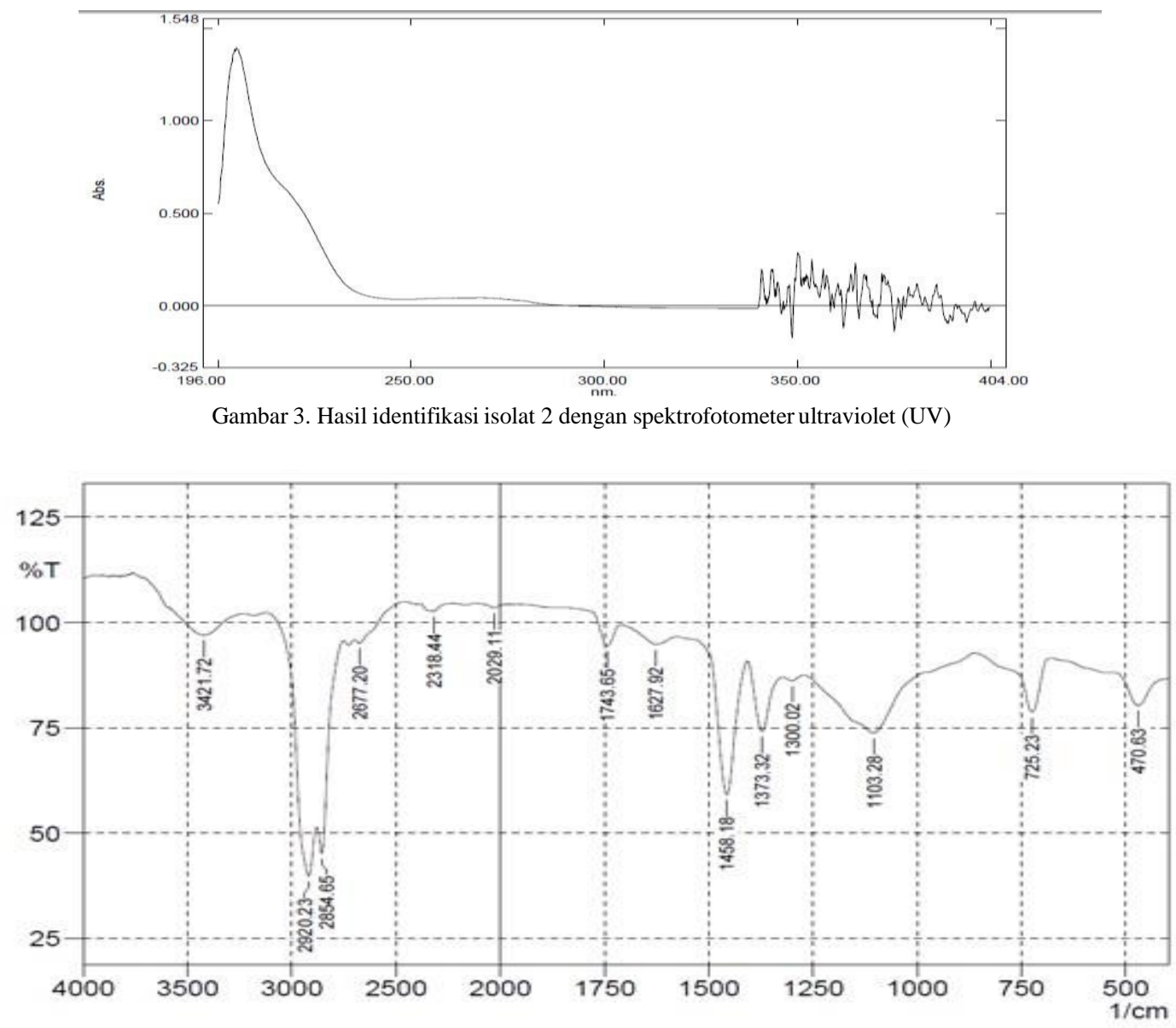

Gambar 4. Hasil identifikasi isolat 2 dengan spektrofotometer inframerah (IR)

\section{Kesimpulan}

Hasil isolasi diperoleh dua isolat yaitu isolat 1 (noda 1) dan isolat 2 (noda 3). Hasil karakterisasi isolat dengan menggunakan spektrofotometer ultraviolet (UV) dan spektrofotometer inframerah (IR). Hasil identifikasi isolat 1 adalah absorpsi maksimum pada panjang gelombang $208 \mathrm{~nm}$, spektrum inframerah menunjukkan ada gugus $-\mathrm{OH}$, $\mathrm{C}=\mathrm{C},-\mathrm{CH} 2,-\mathrm{CH} 3$ dan $\mathrm{C}-\mathrm{O}$. Uji pendahuluan dengan pereaksi Liebermann-Burchard menghasilkan warna merah ungu diduga isolat 1 termasuk golongan saponin triterpenoida dan juga hasil identifikasi isolat 2 adalah absoprsi maksimum pada yaitu panjang gelombang $204 \mathrm{~nm}$, spektrum inframerah menunjukkan ada gugus $-\mathrm{OH},-\mathrm{CH} 2$, $\mathrm{CH} 3$ dan $\mathrm{C}-\mathrm{O}$, Uji pendahuluan dengan pereaksi Liebermann-Burchard menghasilkan warna biru diduga isolat 2 termasuk golongan saponin steroid.

\section{Referensi}

[1] Ajmiati, H., Haryoto, dan Suhendi, A. (2014). Aktivitas Antibakteri Ekstrak Etanol Daun Buni (Antidesma Bunius L. Spreng) Terhadap Escherichia Coli Dan Staphylococcus Aureus Sensitif Dan Multiresisten Serta Bioautografinya. Naskah Publikasi. Surakarta: Universitas Muhammadiyah Surakarta. Halaman 1-12.

[2] Amelia, F., Afnani, G.N., Musfiroh, A., Fikriyani, A.N., Ucche, S., dan Murrukmihadi, M. (2013).Extraction and Stability Test of Anthocyanin from Buni Fruits (Antidesma Bunius L) as an Alternative Natural and Safe Food Colorants. J.Food Pharm.Sci., 1: $49-53$.

[3] Barcelo, J.M., Nullar, A.R.M., Caranto, J.K.P., Gatchallan, A.M., dan Aquinom I.J.B. (2016). Antioxidant and Anti-mutagenic Activities of Ripe Bignay (Antidesma bunius) Crude Fruit Extract. Philipine e-journal for Applied Research and Develompent, 6: 32-43.

[4] Butkhup, L., dan Samappito, S. (2008). Analysis on Flavonoids Contents in Mao Luang Fruits of Fifteen Cultivars (Antidesma bunius), Grown in Northeast Thailand. Pakistan Journal of Biological Sciences, 11 (7): 996-1002. 
[5] Butkhup, L., dan Samappito, S. (2011). Changes In Physico-Chemical Properties, Poly-phenol Compounds and Anti-radical Activity During Development and Ripening of Maoluang (Antidesma bunius L. Spreng) Fruits. Journal of Fruits and Ornamental Plant Research, 19 (1):85-99.

[6] Ditjen POM. (2000). Parameter Standar Umum Ekstrak Tumbuhan Obat. Jakarta: Departemen Kesehatan RI. Halaman 1, 10-11.

[7] Elya, B., Malik, A., Septimaharani, P.I., dan Loranza, B. (2012). Antidiabetic Activity Test by Inhibition of $\alpha$-Glucosidase and Phytochemical Sreening from the Most Active Fraction of Buni (Antidesma bunius L. Spreng) Stem Barks and Leaves. International Journal of PharmTech Research, 4(4): 1667-1671.

[8] Garai, S. (2014). Triterpenoid Saponin. Natural Product Chemical Research, 2(6):1-13

[9] Harborne, J.B., (1987). Metode Fitokimia. Bandung: ITB. Halaman 151-157.

[10] Herrera, S.M.D., Panopi, A.M., Pedrezuel, H.J.C., dan Perez, R.F. (2010). Antiglycemic effect of Bignay (Antidesma bunius) flavonoids in Sprague Dawley rats. The STETH, 4: 1-9.

[11] Hostettmann, K., Hostettmann, M., dan Marston, A. (1995). Cara Kromatografi Preparatif: Penggunaan Pada Isolasi Senyawa Alam. Penerjemah: Kokasih Padmawinata. Bandung: ITB. Halaman 9-12, 33-34.

[12] Kassem, M., Hashim, A.N., dan Hassanein H.M. (2013). Bioactivity Of Antidesma bunius Leaves (Euphorbiaceae) And Their Major Phenolic Constituents. European Scientific Journal, 9 (18): 217-228.

[13] Kumalasari, F., Haryoto, dan Suhendi, A. (2014). Aktivitas Antibakteri Fraski Polar, Semipolar, dan Nonpolar Ekstrak Etanol Daun Buni (Antidesma bunius (L.) Spreng) Terhadap Escherichia Coli Dan Pseudomonas aeruginosa Sensitif Serta Bioautografinya. Naskah Publikasi. Surakarta: Universitas Muhammadiyah Surakarta. Halaman 1-11.

[14] Loranza, B. (2012). Uji Penghambatan Aktivitas Enzim Alfa-Glukosidase dan Identifikasi Golongan Senyawa Kimia dari Fraksi Teraktif Daun Buni (Antidesma bunius L.). Skripsi. Depok: Universitas Indonesia. 1-64.

[15] Micor, J.R.L., Deocaris, C.C., dan Mojica, E.R.E. (2005). Biological Activity of Bignay [Antidesma bunius (L.) Spreng] Crude Extract in Artemia salina. Journal Medicine Science, 5(3): 195-198.

[16] Netala, V.R., Ghosh, S.B., Bobbu, P., Anitha, D., dan Tartte, V. (2015). Triterpenoid Saponins: a Review on Biosynthesis, Applications and Mechanism of their Action. Internasional Journal of Pharmacy and Pharmaceutical Sciences, 7(1): 24-27.

[17] Puspitasari, E., dan Ulfa, E.U. (2009). Uji Sitotoksisitas Ekstrak Metanol Buah Buni (Antidesma bunius (L) Spreng) terhadap Sel Hela. Jurnal Ilmu Dasar, 10(2): 181-185.

[18] WHO. (1998). Quality Control Methods for Herbal Materials. Switzerland: Printed in Malta. Hal. 33-35. 